\title{
The nature of the profession
}

\author{
Catharsis: On the Art of Medicine \\ Andrzej Szczeklik \\ University of Chicago Press; 2005 \\ 161 pp \$20.00 ISBN 0-226-78869-5
}

W

hy is a book on the essential art of medicine still getting rave reviews? Andrzej Szczeklik, a Polish cardiologist and scientist, is no stranger to high tech, life-saving interventions. But he is also familiar with the limits of science and how these limits affect physicians and their patients.

The problem with medicine as pure physiology, as a strictly empirical science, is that its objective - human health - resists any straightforward definition. Health is never construed as "health alone," an idealized pristine state of inertia, a lack of disturbance, but rather as something that is acquired and lost in a continual process through the course of one's life. If health is an active process in which individuals participate, does it not follow that adversity or sickness is somehow related? Szczeklik connects these life situations using the Platonic myths of Fate and Necessity, and weaving case reports and current scientific developments into philosophical themes relevant to medicine - the pursuit of healing (the Philosopher's Stone) and the universal experiences of Suffering and Death. The result takes us somewhere inaccessible to science: the worlds of values, art, faith and other individual phenomena (page 139).

Balancing titans, heroes, medical history and individual accounts is tough to pull off, but the author manages a unique, even poetic synthesis (with only minor imprecision around the emerging science of cloning). Catharsis holds together and is attractive to physicians because it grounds ideas in the concrete relationships between doctors and their patients. The ancient relationship between the suf-

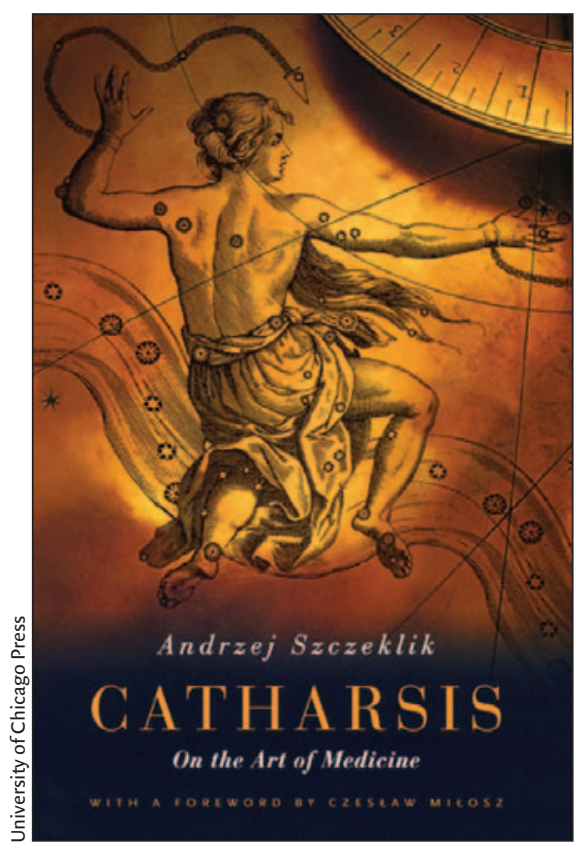

fering individual and his or her physician revolves around an understanding that we are always something more than the single meaning the surrounding world (including medicine) tries to impose on us, the world of simplified generalizations and reductions, the world of clumsy divisions (page 85). In Einstein's words: "Living matter and clarity are opposites - they run from one another" (page 136 ).

This book is itself a chimera, more than an erudite collection of mythology, history and anecdote. It is a thoughtful expression of a life dedicated to medicine, a tension between the need for science to identify reproducible patterns while addressing the art of the singular. As Szczeklik, reaching the end of his own successful career reveals, "When the years start to add up, time goes ever faster and the shadow line is far behind us, we start to feel a longing to understand the nature of the profession that has swallowed up our life."

\section{Dorian Deshauer MD MSc Associate Editor, $C M A J$}

\section{Notes}

\section{Snapshot}

Five $\mathrm{pm}$... you are the last consult, the end of a busy Friday of a busy week ...

I review your chart ... heart failure, diabetes, ACE inhibitors (if you're going to take an inhibitor, might as well be an ace!).

You live in a private room at the end of the hall ... you are sitting upright on the edge of your bed, in a chocolate brown bathrobe ... your blue denim underwear is down around your knees ... you seem to be staring at them ...

The nurse stands you up and offers to help with your shorts ... "Should we pull them up or down?" she says good naturedly. You yank them up, with an 'I can still do that!' look.

Your face is unshaven; your thick white eyebrows gather in the middle, owl-like. Our gazes meet. I see defeat, with hints of selfrespect and humour.

You sit back down, and with a wave of a hand, invite me to do likewise. I sit in your wheelchair, facing you. The late afternoon sun is blazing behind. I position my head so you are between me and the sun. We begin to talk. Each time you move your head, I am blinded by the sun, so each time I reposition mine. I can only see you when you block the light.

"I'm just a crazy old man waiting to die."

We talk some more.

On your bedside table, beside the plastic pitcher of ice water, is a shiny black iPod and speakers. I congratulate you on having such a slick sound system.

"I can't get it to work," you say.

\section{Paul McIntyre MD}

Head, Division of Palliative

Medicine

Capital Health

Halifax, NS 